\title{
Expression of cytoplasmic p16 and anion exchanger 1 is associated with the invasion and absence of lymph metastasis in gastric carcinoma
}

\author{
QIANG LIU ${ }^{1 *}$, LING-JUN SONG $^{2 *}$, WEI-QING XU², LEI ZHAO ${ }^{2}$, \\ LIN ZHENG $^{2}$, ZHAO-WEN YAN ${ }^{2}$ and GUO-HUI FU ${ }^{2}$ \\ ${ }^{1}$ Department of Pathology, Renji Hospital, Shanghai Jiao Tong University School of Medicine, \\ Shanghai 200127; ${ }^{2}$ Department of Pathology, Key Laboratory of Cell Differentiation \\ and Apoptosis of the Chinese Ministry of Education, Institutes of Medical Sciences, \\ Shanghai Jiao Tong University School of Medicine, Shanghai 200025, P.R.China
}

Received November 6, 2008; Accepted December 29, 2008

DOI: 10.3892/mmr_00000079

\begin{abstract}
The tumor suppressor p16 is a negative regulator of the cell cycle, commonly believed to act in the nucleus. We recently found that 16 protein is expressed in the cytoplasm of gastric cancer cells, concomitantly with anion exchanger 1 (AE1). The aim of this study was to analyze the significance of cytoplasmic p16 and its relationship to AE1 in the progression of gastric cancer. Expression of p16 and AE1 was examined by immunohistochemical analysis in 196 patients; 98 with early gastric cancer and 98 with advanced gastric cancer. The relationship between cytoplasmic p16 and clinicopathological features, and the relationship between cytoplasmic p16 and AE1, were analyzed statistically. Expression of p16 was observed in the nucleus in early stage gastric cancer, but was located mainly in the cytoplasm in advanced cancer cells. Furthermore, cytoplasmic expression of p16 was correlated with AE1 expression, and both were associated with the absence of lymph metastasis in gastric cancer. In conclusion, cytoplasmic immunoreactivity of p16 appears to be a good prognostic indicator in advanced gastric cancer. Co-localization of p16 and AE1 predicts a lack of metastasis in gastric cancer. The role of cytoplasmic p16 and AE1, and the mechanisms involved in the progression of gastric cancer, warrant further investigation.
\end{abstract}

Correspondence to: Dr Guo-Hui Fu, Department of Pathology, Shanghai Jiao Tong University School of Medicine, No. 280, South Chong-Qing Road, Shanghai 200025, P.R. China

E-mail: fuguhu@263.net; guohuifu@shsmu.edu.cn

${ }^{*}$ Contributed equally

Key words: cytoplasmic p16, anion exchanger 1, gastric carcinoma, invasion, lymph metastasis

\section{Introduction}

The p16 gene, which maps to chromosome 9p21, encodes a protein of 156 or 148 amino acids. The p16 protein interacts with CDK4/6, which was originally identified from a yeast two hybridization (YTH) screen using CDK4 as the bait protein $(1,2)$. Overexpression of p16 inhibits CDK4/6 activity, leading to hypophosphorylated $\mathrm{pRb}$, reduced $\mathrm{E} 2 \mathrm{~F}$ activity and arrest in the $G_{1}$ phase of the cell cycle. Thus, the main biological function of $\mathrm{p} 16$ is the negative regulation of the cell cycle via the $\mathrm{p} 16 / \mathrm{CDK} 4 /$ cyclin D/Rb pathway $(3,4)$. Subsequent studies have led to the understanding that the p16 protein might be a general regulator, involved in other cellular signaling pathways through its interactions with proteins other than CDK4/6.

Meanwhile, enormous effort has been expended in investigating biological behavior in a wide variety of human malignancies and transformed cell lines. Through these investigations, the functional inactivation of p16 has been observed $(5,6)$. Homozygous deletions and transcriptional silencing by promoter hypermethylation have been found in many cancer cells; these may be mechanisms of p16 inactivation $(7,8)$, suggesting that the inactivation of p16 may be a crucial event in the development of human tumors. However, the exact mechanisms involved in the inactivation of p16 have not been elucidated. Recent studies revealed that the 16 protein was expressed in the cytoplasm in some tumors, suggesting that cytoplasmic distribution of p16 might indicate an inactive form of the protein. The mechanisms involved and the significance of the intracellular localization of the p16 protein are not clear (9-11).

Human anion exchanger 1 (AE1, also called Band 3) is normally expressed in the RBC plasma membrane. Its truncated form, lacking the N-terminal 69 amino acid residues, is also expressed in the kidney. AE1 mediates the exchange of $\mathrm{Cl}^{-}$for $\mathrm{HCO}_{3}{ }^{-}$across the plasma membrane, and is thereby involved in the regulation of intracellular $\mathrm{pH}$ and volume (12-14). AE1 is composed of three functional domains. The 45-kDa N-terminal domain and the acidic C-terminal tail 
(approximately 40 residues) of AE1 are both located in the cytoplasm. The central 55-kDa transmembrane domain spans the bilayer 12-14 times and is responsible for anion transport activity. The N-terminal region of the protein binds ankyrin and other erythrocyte cytoskeletal elements. The C-terminus affects anion transport activity and is likely involved in the three-dimensional structure of AE1 protein (15-17).

AE1 is a novel binding partner of p16. This relationship was identified by YTH using the C-terminal 112 residues of AE1 as bait (18). Subsequent studies have confirmed the interaction of AE1 with p16 in vivo and in vitro. Functional analysis has shown that the function of AE1 differs in gastric cancer cells as compared with normal cells. Silencing the expression of AE1 in gastric cancer cells results in the release of p16 to the nucleus and subsequent cell death. This suggests a mechanism for the cytoplasmic localization of p16, but the details remain to be investigated (19).

To verify the relationship between cytoplasmic p16 and $\mathrm{AE} 1$ in the progression of gastric cancer, the expression of $\mathrm{p} 16$ and AE1 was examined by immunohistochemical analysis in 98 early stage gastric cancers and in 98 advanced stage gastric cancers. The relationships between both cytoplasmic p16 and clinicopathological features and cytoplasmic p16 and AE1 were analyzed.

\section{Materials and methods}

Specimens. A total of 196 patients with gastric cancer treated between 2001 and 2007 at Renji Hospital, Shanghai Jiao Tong University School of Medicine were studied retrospectively. Ninety-eight of these patients had early stage gastric cancer, and 98 had advanced stages of the disease. The University Ethics Committee approved the research protocol. Follow-up data were obtained from medical records.

Immunohistochemical staining. Tumor specimens were fixed in $4 \%$ neutralized formaldehyde, embedded in paraffin and sliced into 4- $\mu \mathrm{m}$ sections, which were stained with hematoxylin and eosin (H\&E). Histological subtypes of gastric carcinoma were defined in terms of Lauren's classification, and the staging for each gastric carcinoma was evaluated according to TNM staging guidelines. Anti-human p16 (ZJ11, 1:70, Maixin-Bio) or AE1 (BIII-136, 1:300, Sigma) monoclonal antibodies were used to detect the expression of p16 or AE1 protein. Deparaffinized sections were treated with $0.3 \% \mathrm{H}_{2} \mathrm{O}_{2}$ for 10 min to block endogenous peroxidase, and were subjected to antigen retrieval by citric acid ( $\mathrm{pH}$ 6.0). Each specimen was washed 3 times for 5 min in PBS ( $\mathrm{pH} 7.4)$. After overnight incubation with primary anti-p16 or AE1 antibodies at $4^{\circ} \mathrm{C}$, the sections were incubated for $15 \mathrm{~min}$ at room temperature with horseradish peroxidase-labeled polymer conjugated with secondary antibody (Max-Vision ${ }^{\mathrm{TM}}$ Kits) and were incubated with diaminobenzidine for $5 \mathrm{~min}$. Control experiments were performed using the same protocols and time exposures. All sections were evaluated by two independent observers (W.-Q. Xu and L.-J. Song) unaware of the disease outcome. Distinct staining was considered to be positive, regardless of the staining intensity. Less than $10 \%$ expression was considered to represent loss (-), and 11-25\%, 26-50\%, and $>51 \%$ expression were designated,+++ , and +++ respectively.
Cell culture. Human normal gastric mucosae (Ges-1) and gastric cancer cell lines (MKN45, SGC7901 and AGS) were obtained from the Shanghai Cell Bank of the Chinese Academy of Sciences. Cells were cultured in DMEM, supplemented with $100 \mathrm{U} / \mathrm{ml}$ penicillin, $100 \mu \mathrm{g} / \mathrm{ml}$ streptomycin and $10 \%$ fetal bovine serum in a humidified atmosphere of $5 \% \mathrm{CO}_{2}$ at $37^{\circ} \mathrm{C}$.

Western blot analysis. Protein (40 $\mu \mathrm{g})$ extracted from cells (Ges-1, SGC7901, MKN45 and AGS) was resolved by sodium dodecyl sulfate-polyacrylamide gel electrophoresis (SDSPAGE) and transferred to a PVDF membrane. All target proteins were immunoblotted by the appropriate primary antibody: anti-p16 (Santa Cruz Biotechnology, CA, USA). Anti-actin antibody (Sigma, St. Louis, MO, USA) was used as an internal loading control. Antigen-antibody complexes were visualized using the ECL reagent (Pierce).

Statistical analysis. Statistical evaluation was performed using the $\chi^{2}$ test to analyze the rank data. Differences of $\mathrm{P}<0.05$ were considered statistically significant. SPSS 11.0 software (Chicago, IL) was used to analyze the data.

\section{Results}

In this study, we detected the expression of p16 and AE1 protein by immunohistochemistry in gastric cancer tissues obtained from surgical resection and endoscopic biopsy. Four different expression patterns of p16 were observed in gastric cancer and its para-cancer cells. Fig. 1a shows a gastric cancer at an early stage (x10). The cancer and para-cancer cells are shown in Fig. 1b and c, respectively (x40). Expression of p16 was demonstrated in the cytoplasm of the cancer cells (Fig. 1b) and in the nucleus of para-cancer cells (Fig. 1c). In addition, p16 expression was particularly pronounced in either the cytoplasm (Fig. 1d) or the nucleus (Fig. 1e) of the cancer cells, and the p16 protein was upregulated in primary gastric cancer tissue and cell lines (MKN45 and AGS) compared with paracancer tissue (Fig. 1a) or the normal gastric mucosa cell line Ges-1 (Fig. 1f).

The distribution of p16 expression in early and advanced stage gastric cancer is shown in Table I. In cells of early stage gastric cancer, p16 was found in the nucleus in $17.2 \%$ of cells, in the cytoplasm in $25 \%$, and in both the nucleus and cytoplasm in $57.8 \%$. In advanced stage gastric cancer, cytoplasmic p16 was significantly greater $(54.5 \%)$, whereas nuclear p16 expression was less $(1.8 \%)$. Both nuclear and cytoplasmic p16 expression was demonstrated in $43.9 \%$ of cancer cells in advanced stage gastric cancer.

We also observed that $57(58.2 \%)$ of 98 cases of advanced gastric carcinoma had detectable expression of p16. In early stage gastric carcinoma, p16 expression was demonstrated in $64(65.3 \%)$ of 98 cases. Thus, advanced gastric cancer had a lower frequency of expression of p16. These results suggest that cytoplasmic p16 is associated with the progression of gastric cancer.

These findings raise questions regarding the significance of cytoplasmic p16, and whether cytoplasmic p16 is related to clinical outcome. Therefore, we next analyzed the relationship between cytoplasmic p16 expression and clinicopathological 


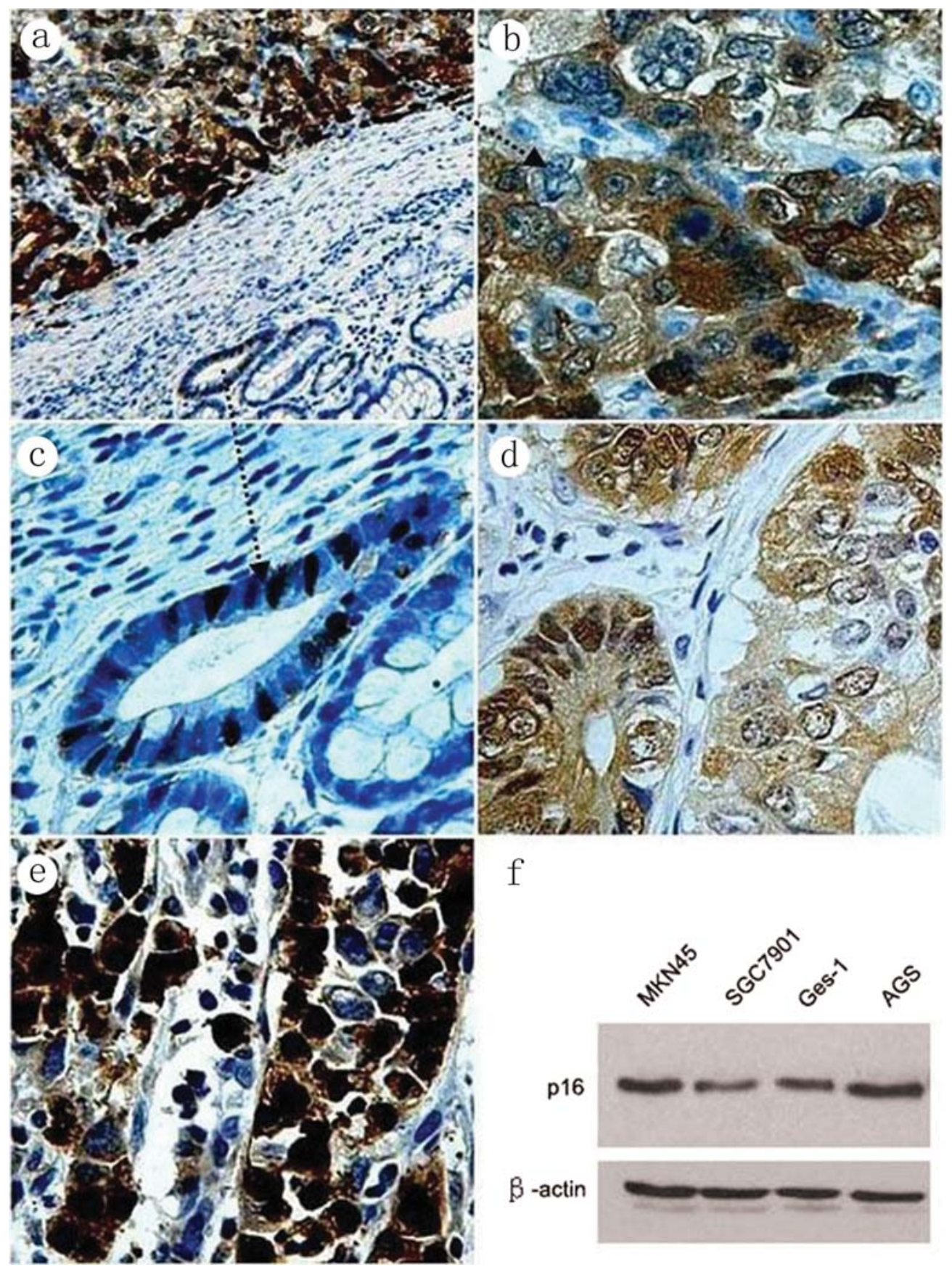

Figure 1. Expression patterns of p16 in gastric cancer. (a) Positive expression of p16 in gastric carcinoma and para-cancer tissue (original magnification x10). (b) Cytoplasmic expression of p16 in gastric cancer tissue (original magnification x40). (c) Nuclear expression of p16 in para-cancer tissue (original magnification $\mathrm{x} 40$ ). (d) Cytoplasmic and nuclear expression of p16 (cytoplasm expression higher) in gastric cancer tissue (original magnification $\mathrm{x} 40$ ). (e) Cytoplasmic and nuclear expression of p16 (nuclear expression higher) in gastric cancer tissue (original magnification $\mathrm{x} 40$ ). (f) Expression level of p16 in gastric cancer and normal gastric cell lines.

Table I. Distribution of location of p16 expression in early and advanced gastric cancer.

\begin{tabular}{|c|c|c|c|c|c|}
\hline \multirow[b]{2}{*}{ Location } & \multicolumn{2}{|c|}{ Early stage } & \multicolumn{2}{|c|}{ Advanced stage } & \multirow[b]{2}{*}{ P-value } \\
\hline & Positive number & Distribution (\%) & Positive number & Distribution (\%) & \\
\hline Nucleus & 64 & $17.2\left(11^{\mathrm{a}}\right)$ & 57 & 1.8 & 0.000 \\
\hline Cytoplasm & 64 & $25.0(16)$ & 57 & $54.4(31)$ & \\
\hline Nucleus and cytoplasm & 64 & $57.8(37)$ & 57 & $43.9(25)$ & 0.008 \\
\hline
\end{tabular}

aPositive number. 
Table II. Association of cytoplasmic p16 expression and clinicopathological features of advanced gastric carcinomas.

\begin{tabular}{|c|c|c|c|c|c|c|c|}
\hline \multirow[b]{3}{*}{$\begin{array}{l}\text { Clinicopathological } \\
\text { features }\end{array}$} & \multirow[b]{3}{*}{ No. } & \multicolumn{5}{|c|}{ p16 expression } & \multirow[b]{3}{*}{ P-value ${ }^{b}$} \\
\hline & & \multirow{2}{*}{$\begin{array}{l}\text { Negative } \\
\text { No. (\%) }\end{array}$} & \multicolumn{4}{|c|}{ Positive } & \\
\hline & & & $\begin{array}{l}\text { Nucleus } \\
\text { No. }(\%)\end{array}$ & $\begin{array}{l}\text { Cytoplasm } \\
\text { No. }(\%)\end{array}$ & $\begin{array}{l}\text { Blend }^{\mathrm{a}} \\
\text { No. }(\%)\end{array}$ & $\begin{array}{c}\text { Cytoplasm blend } \\
(\%)\end{array}$ & \\
\hline Age (years) & & & & & & & 0.725 \\
\hline$<75$ & 55 & $24(43.6)$ & $2(3.6)$ & $16(29.1)$ & $13(23.6)$ & 56.4 & \\
\hline$\geq 75$ & 44 & $18(40.9)$ & $2(4.5)$ & $15(34.1)$ & $9(20.5)$ & 59.1 & \\
\hline Gender & & & & & & & 0.305 \\
\hline Male & 53 & $25(47.2)$ & $0(0.0)$ & $13(24.5)$ & $15(28.3)$ & 52.8 & \\
\hline Female & 46 & $17(37.0)$ & $4(8.7)$ & $18(39.1)$ & $7(15.2)$ & 63.0 & \\
\hline Tumor size $\left(\mathrm{cm}^{3}\right)$ & & & & & & & 0.405 \\
\hline$<4$ & 7 & $2(28.6)$ & $0(0.0)$ & $1(14.3)$ & $4(57.1)$ & 71.4 & \\
\hline$\geq 4$ & 90 & $40(44.4)$ & $4(4.4)$ & $28(31.1)$ & $18(20.0)$ & 55.6 & \\
\hline Lymph metastasis & & & & & & & 0.033 \\
\hline$(-)$ & 19 & $4(21.1)$ & $0(0.0)$ & $10(52.6)$ & $5(26.3)$ & 78.9 & \\
\hline$(+)$ & 78 & $37(47.4)$ & $4(5.1)$ & $20(25.6)$ & $17(21.8)$ & 52.6 & \\
\hline Lauren classification & & & & & & & 0.067 \\
\hline Intestinal type & 26 & $15(57.7)$ & $2(7.7)$ & $4(15.4)$ & $5(19.2)$ & 42.3 & \\
\hline Diffuse type & 73 & $27(37.0)$ & $2(2.7)$ & $27(37.0)$ & $17(23.3)$ & 63.0 & \\
\hline
\end{tabular}

${ }^{\mathrm{a}} \mathrm{p} 16$ was expressed in both the cytoplasm and nucleus. ${ }^{\mathrm{b}}$ Comparison of p16 expression (including cytoplasm and blend) with negative expression.

Table III. Correlation between the expression of AE1 and p16 in tumor cells of advanced gastric carcinoma.

\begin{tabular}{llc}
\hline Grade $^{\mathrm{a}}$ & \multicolumn{2}{c}{ Late gastric carcinomas $(\mathrm{n}=98)$} \\
\cline { 2 - 3 } & $\mathrm{AE} 1(\%)$ & $\mathrm{p} 16(\%)$ \\
\hline 1 & $45.9\left(45 / 98^{\mathrm{c}}\right)$ & $41.8(41 / 98)$ \\
2 & $21.4(21 / 98)$ & $23.5(23 / 98)$ \\
3 & $18.4(18 / 98)$ & $21.4(21 / 98)$ \\
4 & $14.3(14 / 98)$ & $13.3(13 / 98)$ \\
\hline
\end{tabular}

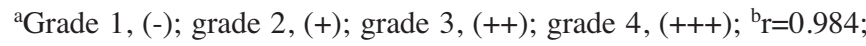
$\mathrm{P}=0.016$. ${ }^{\mathrm{c}}$ Positive number/total number.

features. No significant relationship was found by comparing the separate groups (negative, nuclear, cytoplasmic, or both nuclear and cytoplasmic); however, total expression of cytoplasmic p16 (including exclusively cytoplasmic expression, as well as nuclear and cytoplasmic expression) was significantly correlated with the absence of lymph node metastasis (Table II, $\mathrm{P}=0.033$ ).

Since we previously found that p16 directly binds to the AE1 C-terminus, we next analyzed the association of cytoplasmic p16 with AE1 in terms of frequency of expression, and the relationship between the two proteins and lymph node
Table IV. Association of p16 and AE1 expression and the clinicopathological features of advanced gastric carcinomas.

\begin{tabular}{lcccc}
\hline & \multicolumn{3}{c}{ Lymph node metastasis } & \\
\cline { 3 - 4 } & No. & Negative & Positive & P-value \\
\hline AE1 (-) P16 (-) & 22 & $1\left(4.5^{\mathrm{a}}\right)$ & $21(95.5)$ & 0.046 \\
AE1 (+) P16 (+) & 33 & $10(30.3)$ & $23(69.7)$ & \\
\hline
\end{tabular}

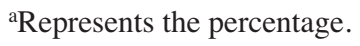

metastasis. We found a significant correlation between AE1 and p16 in both expression frequency (Table III, $\mathrm{r}=0.984$, $\mathrm{P}=0.016$ ) and absence of lymph node metastasis (Table IV, $\mathrm{P}=0.046)$.

\section{Discussion}

Since p16 was identified as a protein that negatively regulates the cell cycle, it was generally believed that p16 functioned in the nucleus; however, to date, there has been no direct evidence to support this assumption. On the contrary, increasing reports have demonstrated the cytoplasmic localization of p16 in different primary tumor cells, such as breast, lung and prostate carcinoma cells, suggesting that cytoplasmic p16 is associated with carcinogenesis (20-23). However, results concerning the 
relationship between cytoplasmic p16 and clinical features are inconsistent. In primary breast carcinoma, reports indicate that cytoplasmic expression of p16 is associated with unfavorable prognosis; however, no association between cytoplasmic p16 and patient outcome has been described (24).

In the present study, p16 was expressed in the nucleus and cytoplasm of cancer cells in the early stages of gastric cancer, but was mainly expressed in the cytoplasm in advanced stages of the disease. As shown in Table I, in the series of 121 gastric cancer specimens with positive p16 expression, cytoplasmic p16 protein was found in $25 \%$ of early gastric carcinomas, but was found with greater intensity in advanced gastric carcinoma, and in a higher percentage of cases (54.4\%). This suggests that cytoplasmic p16 staining increases along with the progression of gastric cancer. Cytoplasmic p16 is therefore associated with the depth of invasion of gastric cancer, by virtue of the fact that the distinction between early and advanced gastric cancer is based on the criterion of the depth of invasion of cancer cells. This finding is in agreement with that of another study, in which the authors concluded that the invasion of basal cell carcinoma was induced by p16 upregulation (in both the nucleus and cytoplasm) with the requirement of a functional p16/cyclin $\mathrm{D} / \mathrm{Rb}$ pathway (25).

Although the details of the mechanisms involved in the cytoplasmic accumulation of p16 remain unclear, one piece of solid evidence addressing this issue was previously reported by our group. We found that AE1 was unexpectedly expressed in gastric cancer cells, and that it interacted with p16. This resulted in the sequestration of p16 protein in the cytoplasm. Expression of AE1 was also correlated with deeper invasion (data not shown). This observation is consistent with our observations in the present study. Other hypotheses have been presented in several reports, including the mutation of nuclear localization signals and the deregulation of p16 chaperone proteins $(22,26)$. In addition, we found p16 overexpression in advanced gastric carcinoma. Studies have shown that p16 is expressed at very low levels in normal gastric epithelium, and that the overexpression of p16 is associated with tumor progression and poor prognosis $(27,28)$. These findings suggest that p16, acting as a negative cell cycle regulator, may also take part in carcinogenesis.

In contrast to its association with cancer invasion, cytoplasmic p16 is correlated with the absence of lymph node metastasis. This observation raises a bewildering question regarding the role of cytoplasmic p16 in the progression of gastric cancer. Invasion and metastasis are two properties which contribute to the serious consequences of cancer $(29,30)$. Invasion is associated with increased cellular motility, increased proteolytic activity of enzymes, and alterations in cell adhesion. Metastasis is the process whereby malignant tumor cells spread from their site of origin to distant sites in the body. In a general way, invasion and metastasis are likely to be manifestations of the same properties of tumor cells; however, experimental results and clinical observations have shown that different signal pathways mediate the processes of invasion and metastasis. For example, some early stage carcinomas metastasize to distant organs, whereas other carcinomas of advanced stages do not metastasize until a later time. The results suggest that cytoplasmic p16 expression can influence the phenotype of a tumor cell to be invasive with low potential for metastasis, suggesting that the tendency of tumor cells to invade or to metastasize could be predicted by the observation of p16 activity, and that invasion and metastasis represent two distinct aspects of malignant behavior.

As we demonstrated previously, transient expression of AE1 upregulates the expression of endogenous p16 protein, and the enhanced expression of p16 facilitates the movement of AE1 to the plasma membrane in the human embryo kidney cell line HEK293 (18). By contrast, in gastric cancer cells, AE1 was unconventionally expressed and failed to move to the plasma membrane, thus resulting in the sequestration of p16 in the cytoplasm (19). In addition, expression of AE1 was correlated with the absence of lymph node metastasis (data not shown). This observation is consistent with the relationship between cytoplasmic p16 and clinical outcome in gastric cancer. The expression of p16 in the cytoplasm is at least in part due to the sequestration of AE1. Co-expression of AE1 could affect the construction and the function of cytoskeletal protein, because the AE1 protein interacts with several cytoskeletal proteins that play a crucial role in the metastasis of cancer $(31,32)$.

\section{Acknowledgements}

This work was supported in part by the Project of the National Natural Science Foundation of P.R. China (NO30570697; 30770960).

\section{References}

1. Serrano M, Hannon GJ and Beach D: A new regulatory motif in cell-cycle control causing specific inhibition of cyclin D/CDK4. Nature 16: 704-707, 1993.

2. Kamb A, Gruis NA, Weaver-Feldhaus J, et al: A cell cycle regulator potentially involved in genesis of many tumor types. Science 264: 436-440, 1994.

3. Sherr CJ: Principles of tumor suppression. Cell 23: 235-246, 2004.

4. Fåhraeus R, Paramio JM, Ball KL, Laín S and Lane DP: Inhibition of $\mathrm{pRb}$ phosphorylation and cell-cycle progression by a 20-residue peptide derived from p16CDKN2/INK4A. Curr Biol 6: 84-91, 1996.

5. Reed AL, Califano J, Cairns P, et al: High frequency of p16 (CDKN2/MTS-1/INK4A) inactivation in head and neck squamous cell carcinoma. Cancer Res 56: 3630-3633, 1996.

6. Herman JG, Merlo A, Mao L, et al: Inactivation of the CDKN2/ p16/MTS1 gene is frequently associated with aberrant DNA methylation in all common human cancers. Cancer Res 55: 4525-4530, 1995.

7. Cairns P, Polascik TJ, Eby Y, et al: Frequency of homozygous deletion at p16/CDKN2 in primary human tumours. Nat Genet 11: 210-212, 1995.

8. Muscarella P, Melvin WS, Fisher WE, et al: Genetic alterations in gastrinomas and nonfunctioning pancreatic neuroendocrine tumors: an analysis of p16/MTS1 tumor suppressor gene inactivation. Cancer Res 58: 237-240, 1998.

9. Salvesen HB, Das S and Akslen LA: Loss of nuclear p16 protein expression is not associated with promoter methylation but defines a subgroup of aggressive endometrial carcinomas with poor prognosis. Clin Cancer Res 6: 153-159, 2000.

10. Pei XH and Xiong Y: Biochemical and cellular mechanisms of mammalian CDK inhibitors: a few unresolved issues. Oncogene 24: 2787-2795, 2005

11. Svensson S, Nilsson K, Ringberg A and Landberg G: Invade or proliferate? Two contrasting events in malignant behavior governed by p16(INK4a) and an intact Rb pathway illustrated by a model system of basal cell carcinoma. Cancer Res 63: 1737-1742, 2003.

12. Lux SE, John KM, Kopito RR and Lodish HF: Cloning and characterization of band 3 , the human erythrocyte anion-exchange protein (AE1). Proc Natl Acad Sci USA 86: 9089-9093, 1989. 
13. Jensen FB: Red blood cell $\mathrm{pH}$, the Bohr effect, and other oxygenation-linked phenomena in blood $\mathrm{O}_{2}$ and $\mathrm{CO}_{2}$ transport. Acta Physiol Scand 182: 215-227, 2004.

14. Sterling D, Reithmeier RA and Casey JR: A transport metabolon Functional interaction of carbonic anhydrase II and chloride/ bicarbonate exchangers. J Biol Chem 276: 47886-47894, 2001.

15. Wang Y, Wu SF, Chen GQ and Fu GH: Effect of block deletions in the C-terminus on the functional expression of human anion exchanger 1 (AE1). Mol Membr Biol 24: 65-73, 2007.

16. Fu G, Wang T, Yang B, et al: Purification and characterization of the human erythrocyte band 3 protein C-terminal domain. Biochemistry 43: 1633-1638, 2004.

17. Cordat E, Li J and Reithmeier RA: Carboxyl-terminal truncations of human anion exchanger impair its trafficking to the plasma membrane. Traffic 4: 642-651, 2003.

18. Fu GH, Wang Y, Xi YH, et al: Direct interaction and cooperative role of tumor suppressor p16 with band 3 (AE1). FEBS Lett 579: 2105-2110, 2005.

19. Shen WW, Wu J, Cai L, Liu BY, Gao Y, Chen GQ and Fu GH: Expression of anion exchanger 1 sequestrates p16 in the cytoplasm in gastric and colonic adenocarcinoma. Neoplasia 9: 812-819, 2007.

20. Emig R, Magener A, Ehemann V, et al: Aberrant cytoplasmic expression of the $\mathrm{p} 16$ protein in breast cancer is associated with acce-erated tumour proliferation. Br J Cancer 78: 1661-1668, 1998.

21. Yamazaki T, Tomita S, Ichikawa K, et al: P16-immunostaining pattern as a predictive marker of lymph node metastasis and recurrence in early uterine cervical cancer. Pathobiology 73: 176-182, 2006.

22. Arifin MT, Hama S, Kajiwara Y, et al: Cytoplasmic, but not nuclear, p16 expression may signal poor prognosis in high-grade astrocytomas. J Neurooncol 77: 273-277, 2006.

23. Nilsson K and Landberg G: Subcellular localization, modification and protein complex formation of the cdk-inhibitor p16 in $\mathrm{Rb}$ functional and $\mathrm{Rb}$-inactivated tumor cells. Int J Cancer 118 : 1120-1125, 2006.
24. Straume O, Sviland L and Akslen LA: Loss of nuclear p16 protein expression correlates with increased tumor cell proliferation (Ki-67) and poor prognosis in patients with vertica growth phase melanoma. Clin Cancer Res 6: 1845-1853, 2000.

25. Svensson Månsson S, Reis-Filho J and Landberg G: Transcriptional upregulation and unmethylation of the promoter region of p16 in invasive basal cell carcinoma cells and partial co-localization with the gamma 2 chain of laminin-332. J Pathol 212: 102-111, 2007.

26. Fabbro M, Rodriguez JA, Baer R and Henderson BR: BARD1 induces BRCA1 intranuclear foci formation by increasing RINGdependent BRCA1 nuclear import and inhibiting BRCA1 nuclear export. J Biol Chem 277: 21315-21324, 2002.

27. Lee CT, Capodieci P, Osman I, et al: Overexpression of the cyclin-dependent kinase inhibitor p16 is associated with tumor recurrence in human prostate cancer. Clin Cancer Res 5: 977-983, 1999.

28. Ivanova TA, Golovina DA, Zavalishina LE, et al: Up-regulation of expression and lack of $5^{\prime} \mathrm{CpG}$ island hypermethylation of p16 INK4a in HPV-positive cervical carcinomas. BMC Cancer 7: 47-57, 2007

29. Tryggvason K, Höyhtyä M and Pyke C: Type IV collagenases in invasive tumors. Breast Cancer Res Treat 24: 209-218, 1993.

30. Chambers AF and Matrisian LM: Changing views of the role of matrix metalloproteinases in metastasis. J Natl Cancer Inst 3: 1260-1270, 1997.

31. Salomao M, Zhang X, Yang Y, et al: Protein 4.1R-dependent multiprotein complex: new insights into the structural organization of the red blood cell membrane. Proc Natl Acad Sci USA 105: 8026-8031, 2008.

32. Morris MB and Lux SE: Characterization of the binary interaction between human erythrocyte protein 4.1 and actin. Eur J Biochem 231: 644-650, 1995 